\title{
MusicAl INTELLIGENCE AND FOREIGN LANGUAGE LEARNING
}

\author{
JERZY ZYBERT \\ j.zybert@uw.edu.pl \\ SABINA STĘPIEN \\ University of Warsaw
}

\begin{abstract}
The article discusses the potential advantage that musically gifted FL learners have in developing the speaking skill, especially in acquiring some prosodic features. Empirical findings are provided to support the assumption.
\end{abstract}

Key words: language, music, linguistic intelligence, musical intelligence, foreign language learning

\section{Introduction}

Drawing on the theory of multiple intelligences it seems rational to assume that out of the original eight (Gardner, 1983) two are naturally related with regard to foreign language (FL) learning. These are: linguistic intelligence ("word smart") and musical intelligence ("music smart"). Thus, in line with the postulations advanced by the Multiple Intelligences theory that the learning process will be facilitated provided an appropriate path to learning is adopted, we assume that FL teaching can become definitely much more effective if it takes learners' musical intelligence into consideration. On the other hand, it can be claimed that those students who have a natural gift for music and well developed musical intelligence will make optimal use of their musical aptitude in developing certain FL oral skills and become highly successful language learners if teachers pay appropriate heed to them.

\section{Music and language}

Music, like language, is natural to humankind and as such both phenomena are universal. Music accompanies our everyday activities: it makes learning easier (e.g. chanting helps to memorize longer texts) and also makes effort lighter (just think of work songs harvest songs, rowing songs, marching songs, etc.). What is more, group singing has a social function: it gives participants a strong feeling of cohesion and solidarity. Then again, music can also facilitate language learning; it follows that looking for evidence to confirm the assumed relationship between language learning and music is worth pursuing. Researchers take considerable interest in the language-music link. One 
researcher claims that language and music are crucially similar in "consisting of perceptually discrete elements organized into hierarchically structured sequences" (Patel, 2003: 676). The link has also been documented in neurolingustic research which shows that language areas in the brain, specifically Broca's, are "also implicated in musical processing" (Gunter and Friederici, 2001: 724). Moreover, according to these authors, musical ability is predictive of verbal ability. Again, if the language learning aptitude construct, and especially, phonemic coding ability is accepted, we may equally well assume that a potential for genetically endowed musical ability (musical intelligence) is a likely proposition: "just as the ability to understand spoken language emerges effortlessly in infants, the ability to appreciate music likewise requires no explicit training" (Spiro, 2003: 662).

In the context of the possible influence of musical abilities on learning a foreign language, particularly on the development of oral skills, two questions seem worth exploring; first, is there actually a definite connection between the perception of the sounds of music and of speech?; second, is there a positive connection between the production of music and of FL oral performance, particularly of suprasegmentals? If the answers are positive, we can argue that "music smart" foreign language learners possess good phonemic coding ability, a component of language aptitude (Carroll 1965, in Skehan 1989; Zybert, 2000), which assists them in acquiring a new sound system. Some individuals are able to "produce" what seems to be foreign languages. These people sound and give the impression that they actually speak foreign languages thanks to their tremendous imitative articulatory capability; this exhibits a clear correlation between their mimicry ability and pronunciation in a FL. Incidentally, they are concurrently also musically gifted. FL students who consider themselves musically talented (especially those who can play an instrument) admit that they do not find FL learning very difficult, whereas unsuccessful learners usually do not play any instrument and do find language learning hard, especially its phonetics/phonology.

Music is often used in foreign language classrooms; however, it is usually assigned as an entertaining and/or recreational activity. This is regrettable since music, and in particular songs, can be used as an excellent pedagogical tool in language teaching. With the present day emphasis on using authentic materials for both language learning and for familiarizing learners with foreign culture it is worth noting that songs constitute a highly beneficial component of FL learning - they demonstrate another culture and bring authentic voices from it. On the one hand, listening to songs and singing them strengthen pronunciation skills and, on the other, introduce students to a variety of dialects of the target language. Songs also provide substantial opportunity not only for learning new vocabulary but also for consolidating newly learned vocabulary which becomes reinforced through chorus singing of lyrics. Language learning combined with music facilitates the process as many learners frequently remember rhythm, stress, rhyme, and melody better than spoken language.

Music is expressive; so is language and expressiveness in speech is achieved mostly by means of suprasegmentals: intonation, rhythm, pitch, and stress. Intonation and stressing are of particular importance for comprehension. Poor intonation and stressing require considerable effort on the part of an interlocutor to grasp the intended meaning to the native speaker this deficit acts as a manifestation of a lack of the learner's instinctive feeling for the language. If, as phoneticians sometimes say, the pronunciation 
of the sounds of a language is its body and intonation its soul, then musically gifted FL speakers are lucky in that they are naturally equipped with this particular linguistic soul.

\section{Research}

Mere observation often provides substantial indication of the impact of musical intelligence on learning various aspects of FL seems undeniable. Blickenstaff (1963) alleges that musical abilities affect hearing skills and so positively influence articulation. Thus it only remains to find empirical evidence to support similar claims especially since many FL teachers maintain that proper pronunciation is the most difficult aspect of language learning in general. The research presented below stemmed from the attempt to assess the relationship between musical aptitude and FL learning, both for reception and production, with focus on suprasegmentals. It was hypothesized that music-smart students would outperform non-music-smart students. Therefore it was carried out on learners of English selected deliberately from a music school and a non-music school.

\subsection{Objectives}

The major aim of the research described below was to provide evidence to support the two claims advanced in the Introduction above: i) that a connection exists between music perception and speech perception and ii) that music production links with speech production. In more general terms we assume that musical gift correlates with success in FL learning and that musical training fosters FL learning.

\subsection{Subjects}

Two groups of Polish learners of English, assessed as intermediate, participated in the research. One group consisted of students who are keen on music and the other of those who are not. The label "keen on music" relates to secondary music school students (henceforth MSs = music students), 22 in number, whereas the other group consisted of secondary grammar school (henceforth nMSs = non-music students), 29 in number; altogether 51 students were investigated. They were all first graders, 15-16 years of age, of both genders.

\subsection{Instrumentation}

Four tests were used:

Music Perception Test. To test learners' musical ability Edwin Gordon's Intermediate Measure of Music Audiation was used. This is a brief longitudinally valid music aptitude test suitable for all individuals, including those who have no experience with or liking for music. The original test was slightly modified by a highly qualified 
Music Academy teacher of music to meet the research objectives and consisted of three subtests: one on fall/rise music pattern recognition and two on tone identification.

Speech Perception Test. This test was intended to examine learners' ability to perceive differences in speech production and consisted of tasks that aimed to check their ability to discriminate between vowels and to recognize intonation contours. The tasks were taken from English Pronunciation in Use (Intermediate) by Mark Hancock and played to students from a CD.

Music Production Test. In this test students were required to repeat (imitate) five musical intervals. The notes played to students were varied according to the respective range of their capabilities: with females notes were played for contraltos and sopranos, with males for tenors and baritones. Actually, the range was slightly wider than one octave. The intervals played included the following: perfect fifth, perfect fourth, major third, major second, and augmented fourth.

Speech Production Test. This test intended to measure the students' ability to reproduce short utterances spoken by native English speakers recorded on a CD. The tasks, similarly to those in the Speech Perception Test, were taken from English Pronunciation in Use Intermediate) by Mark Hancock and focused on intonation patterns but evaluation involved also their abilities for imitating a native accent overall, and pronunciation and stress in particular.

\subsection{Test administration}

Apart from the four tests quoted in section 3.3 above, first a questionnaire was administered to students to collect background information on their prior exposure to English and music training. This was done as a precaution: it turned out that some of the non-music students had had some musical experience, which resulted in their test scores being definitely higher than those of the other non-music students. Their scores should be considered as additional corroboration of the music-language relationship claim. All tests, with the exception of the Music Production Test, were given to the two groups of test-takers separately, students being seated so that they were unable to collaborate with one another. Answer sheets were distributed to students before the beginning of each test. The sheets were easy to correct quickly by using scoring masks. Raw scores were directly converted to percentile ranks.

Music Perception Test. The testees took the test by simply listening to the tones played to them in the classroom from a Yamaha S80 keyboard. The pianist played thirty pairs of tones to the students. Each pair was a series of tones that differed by one or more tones. In the first subtest (fall/rise music pattern recognition), students listened to ten music patterns and tried to identify them as rising or falling by putting a slash ( / ) for a rise and a backslash $(\backslash)$ for a fall, respectively, in the appropriate boxes on their answer sheets. In the next subtest (tone identification) students listened to ten pairs of patterns. Having decided that the patterns were the same in a pair the students were to put an S, and when different (some differed by one or more notes) they were to put a D in the appropriate box. In the third subtest ten pairs of music intervals were played and the testees' task was to recognize the intervals in each pair as identical or different and place an $\mathrm{S}$ or a $\mathrm{D}$ in appropriate boxes on the answer sheets. 
Speech Perception Test. This test consisted of four recognition tasks. The students listened to sentences uttered by native speakers of English played from a CD. In the first task seven question-and-answer pairs were played to the learners who were asked to identify the final intonation pattern in response to a question. In the second task, similar to the previous one, eight sentences were played and the students were again to recognize the intonation pattern as rising or falling: they gave their answers in the appropriate boxes in the sheets provided. In the third task ten pairs of sentences were played and the students had to decide whether the speaker pronounced both sentences in a pair alike or not; they indicated their answers with an S (same) or a D (different). The last subtest investigated the students' ability to distinguish vowel qualities. Students listened to eighteen sentences which contained two or three words that sounded similar in each sentence. Their task was to indicate the word in the sentence they believed they recognized.

Music Production Test. In this test students were examined individually. They were required to reproduce (imitate) five musical intervals that were played to them. The notes played corresponded with their gender and singing capability range and the sample of intervals was that quoted in section 3.3 .3 above. The test was conducted by an experienced pianist-music teacher; he played the intervals to the students and assessed their performance giving grades on a scale ranging from 0 to 5 , with zero indicating no musical ability.

Speech Production Test. The students were tested individually in a sound-proof room. Seven short sentences were played to them from a CD and they repeated each successive sentence. A native English teacher evaluated the accuracy of the students' utterances directly, assessing them on the scale from 0 to 5. Grade 0 indicated total lack of imitative ability (admittedly, highly subjective), whereas 5 indicated perfect performance. The marks were put on the student's evaluation sheet.

\subsection{Research findings}

The results of the tests together with appropriate discussions are presented below:

Musical aptitude and language learning. The MSs scored much higher on intonation and music patterns than did the nMSs; however, for the vowel discrimination task the difference was not very striking. Correlations between speech perception and music perception (intonation patterns / tone recognition), were also found. The tables below present the results obtained from the measurement of correlation coefficient (r). Additionally, probability value (p) was measured for the results ${ }^{1}$.

\footnotetext{
${ }^{1}$ According to statisticians, if probability value is less than 0.05 or close to this value results are fairly reliable.
} 
Table 1. The nMSs group

\begin{tabular}{|c|c|}
\hline $\begin{array}{l}\text { Speech Perception/Music Perception } \\
\text { TOTAL SCORES }\end{array}$ & $\begin{array}{l}\mathrm{r}=-0.17 \\
\mathrm{p}=0.1\end{array}$ \\
\hline $\begin{array}{l}\text { Speech Perception/Music Perception } \\
\text { INTONATION RECOGNITION }\end{array}$ & $\begin{array}{l}r=-0.29 \\
p=0.06\end{array}$ \\
\hline $\begin{array}{l}\text { Speech Perception/ Music Perception } \\
\text { TONE PERCEPTION }\end{array}$ & $\begin{array}{l}r=-0.33 \\
p=0.04\end{array}$ \\
\hline Music Production/Speech Production & $\begin{array}{l}\mathrm{r}=0.18 \\
\mathrm{p}=0.17\end{array}$ \\
\hline Music Perception/ Speech Production & $\begin{array}{l}\mathrm{r}=0.19 \\
\mathrm{p}=0.18\end{array}$ \\
\hline Speech Perception/ Music Production & $\begin{array}{l}\mathrm{r}=0.28 \\
\mathrm{p}=0.07\end{array}$ \\
\hline
\end{tabular}

Table 2. The MSs group

\begin{tabular}{|c|c|}
\hline $\begin{array}{l}\text { Speech Perception/Music Perception } \\
\text { TOTAL SCORES }\end{array}$ & $\begin{array}{l}r=0.49 \\
p=0.01\end{array}$ \\
\hline $\begin{array}{l}\text { Speech Perception/Music Perception } \\
\text { INTONATION RECOGNITION }\end{array}$ & $\mathrm{r}=0.14$ \\
\hline $\begin{array}{l}\text { Speech Perception/ Music Perception } \\
\text { TONE PERCEPTION }\end{array}$ & $\begin{array}{l}r=-0.19 \\
p=0.2\end{array}$ \\
\hline Music Production/Speech Production & $\begin{array}{l}\mathrm{r}=0.48 \\
\mathrm{p}=0.01\end{array}$ \\
\hline Music Perception/ Speech Production & $\begin{array}{l}r=0.31 \\
p=0.08\end{array}$ \\
\hline Speech Perception/ Music Production & $\begin{array}{l}r=0.41 \\
p=0.02\end{array}$ \\
\hline
\end{tabular}


Table 3. Both groups

\begin{tabular}{|l|l|}
\hline Speech Perception/Music Perception & $\begin{array}{l}\mathrm{r}=0.49 \\
\mathrm{p}=0.0001\end{array}$ \\
\hline Music Production/Speech Production & $\begin{array}{l}\mathrm{r}=0.38 \\
\mathrm{p}=0.003\end{array}$ \\
\hline Music Perception/ Speech Production & $\begin{array}{l}\mathrm{r}=0.47 \\
\mathrm{p}=0.0005\end{array}$ \\
\hline Speech Perception/ Music Production & $\begin{array}{l}\mathrm{r}=0.46 \\
\mathrm{p}=0.00034\end{array}$ \\
\hline
\end{tabular}

Standardized values, used for establishing the degree of correlation:

$\mathrm{r}<0.2$ : no correlation; $r=0.2-0.4$ : weak correlation; $r=0.4-0.7$ : moderate correlation; $r$ $=0.7-0.9$ : strong correlation; $r>0.9$ : very strong correlation.

The results demonstrate a statistically significant correlation between music and speech production. It is not surprising that the coefficient is higher for the MSs $(r=0.48$ and $\mathrm{p}<0.05)$ than for the nMSs $(\mathrm{r}=0.18$ and $\mathrm{p}>0.05)$; music perception and language perception correlate significantly too $(r=0.49$ and $p<0.05)$ for the MSs group. However, for the other group there is no correlation $(r=-0.17)$. In the nMSs group no correlation for music perception and speech perception is observed: $r$ is -0.33 but $p$ value is greater than 0.05 . The analysis also shows that music perception correlates with speech production $(\mathrm{r}=31, \mathrm{p}=0.08)$, therefore we conclude that students with musical abilities perform better in phonetic tasks than their counterparts and that they have no problems in imitating English intonation patterns. With nMSs such a correlation is practically nonexistent though a significant correlation between speech perception and music production $(\mathrm{r}=0.41, \mathrm{p}<0.05)$ suggests that students who can sing in tune are better in phonetic tasks than those who cannot hear frequencies or repeat tones correctly.

Correlation coefficients calculated for all the data obtained for both groups are statistically significant. Since the probability value (p) is below 0.05 it can be stated that there is a significant difference between data sets. Thus the data established for the MSs differ considerably from those of nMSs, which indicates that musical aptitude is an independent variable responsible for this difference. None of the correlations is very strong; however, the data permit the contention that a musical gift enables language learners to acquire FL phonetic aspects easily whereas its lack does not.

Musical Training and Foreign Language Learning. In order to provide evidence for the claim that musical training can influence FL learning the nMSs completed a questionnaire about their musical background. The questions concerned their experience with music gained by learning to play a musical instrument, singing solo or in a choir, or dancing. The answers made it possible to consider the subjects in two new groups: one with (group A) and the other (group B) without musical training and to subsequently relate them to their test results ${ }^{2}$.

\footnotetext{
${ }^{2}$ Some researchers claim that musical training reinforces the FL learning process in children and adolescents only and does not work for adults.
} 
The comparison of the two groups displayed a clear relationship between musical training and the phonetic aspects of FL learning. Whereas the MSs have relatively little difficulty in articulating FL sounds and producing intonation patterns, students with no musical talent or experience face serious problems in that respect.

Notwithstanding, to verify the assumption that musical experience or training does actually facilitate FL learning another test was administered. It involved the two groups of subjects: group A included all MSs and those nMSs who admitted they had musical experience and group B formed by those nMSs who had no musical experience; the latter group was very small, actually there were only seven such students. The test was intended to compare the mean results for speech production and speech perception. Since the results were expected to be different for the two groups it was important to measure standard deviations for them. The results of unpaired tests are as follows:

\section{Speech Production}

\section{$P$ value and statistical significance:}

The two-tailed $\mathbf{p}$ value equals 0.0066

According to conventional criteria this difference is considered statistically significant.

\section{Confidence interval:}

The mean for group B minus group A equals - 1.673

$95 \%$ confidence interval of this difference: from -2.858 to -0.489

Intermediate values used in calculations: $\mathbf{t}=\mathbf{2 . 8 3 8 7}$

degree of freedom $(\mathbf{d f})=49$

standard error of difference $=0.589$

Table 4

\begin{tabular}{|l|l|l|}
\hline Group & Group One & Group Two \\
\hline Mean & 32.741 & 31.068 \\
\hline Standard Deviation & 1.286 & 2.817 \\
\hline Number of Subjects & 29 & 22 \\
\hline
\end{tabular}

\section{Speech Perception}

$P$ value and statistical significance:

The two-tailed $\mathbf{p}$ value equals 0.0195 According to conventional criteria this difference is considered statistically significant.

\section{Confidence interval:}

The mean for group B minus group A equals -1.748 95\% confidence interval of this difference: from -3.204 to -0.293

Intermediate values used in calculations: $t=\mathbf{2 . 4 1 4 6}$ degree of freedom $(\mathrm{df})=\mathbf{4 9}$ standard error of difference $=0.724$ 
Table 5

\begin{tabular}{|l|l|l|}
\hline Group & Group One & Group Two \\
\hline Mean & 45.362 & 43.614 \\
\hline Standard Deviation & 2.132 & 2.841 \\
\hline Number of Subjects & 29 & 22 \\
\hline
\end{tabular}

Because the $p$ values for Speech Perception and Speech Production tests are less than 0.05 (if we take into account one-tailed results for the $p$ values) the hypothesis of the equality of means has to be rejected. Thus, the factor of musical training was found to have an impact on language learning. Tables 6 and 7 below show correlation coefficients calculated separately for both groups. For group A subjects the correlation between music and language is significant. Moreover the $\mathrm{p}$ values are lower than 0.01 or 0.05 . For group B they are below 0, therefore we can say there is no correlation between music and language in this case. The calculation of correlation coefficient proved again that the two groups differ considerably. Hence, it is assumed that musical training can play a crucial role in FL learning.

Table 6. Students with musical training from both schools

\begin{tabular}{|c|c|}
\hline $\begin{array}{l}\text { Speech Perception/Music Perception } \\
\text { TOTAL SCORES }\end{array}$ & $\begin{array}{l}\mathrm{r}=0.48 \\
\mathrm{p}=0.004\end{array}$ \\
\hline $\begin{array}{l}\text { Speech Perception/Music Perception } \\
\text { INTONATION RECOGNITION }\end{array}$ & $\begin{array}{l}\mathrm{r}=0.55 \\
\mathrm{p}=0.0009\end{array}$ \\
\hline $\begin{array}{l}\text { Speech Perception/ Music Perception } \\
\text { TONE PERCEPTION }\end{array}$ & $\begin{array}{l}r=0.1 \\
p=0.3\end{array}$ \\
\hline Music Production/Speech Production & $\begin{array}{l}\mathrm{r}=0.35 \\
\mathrm{p}=0.03\end{array}$ \\
\hline Music Perceptron/ Speech Production & $\begin{array}{l}\mathrm{r}=0.25 \\
\mathrm{p}=0.09\end{array}$ \\
\hline Speech Perception/ Music Production & $\begin{array}{l}\mathrm{r}=0.22 \\
\mathrm{p}=0.12\end{array}$ \\
\hline
\end{tabular}


Table 7. Students with no musical training

\begin{tabular}{|l|l|}
\hline $\begin{array}{l}\text { Speech Perception } \\
\text { /Music Perception } \\
\text { TOTAL SCORES }\end{array}$ & $\begin{array}{l}\mathrm{r}=-0.16 \\
\mathrm{p}=0.19\end{array}$ \\
\hline $\begin{array}{l}\text { Speech Perception/Music Perception } \\
\text { INTONATION RECOGNITION }\end{array}$ & $\begin{array}{l}\mathrm{r}=-0.29 \\
\mathrm{p}=0.09\end{array}$ \\
\hline $\begin{array}{l}\text { Speech Perception/ Music Perception } \\
\text { TONE PERCEPTION }\end{array}$ & $\begin{array}{l}\mathrm{r}=-0.25 \\
\mathrm{p}=0.1\end{array}$ \\
\hline Music Production/Speech Production & $\begin{array}{l}\mathrm{r}=0.2 \\
\mathrm{p}=0.18\end{array}$ \\
\hline Music Perceptron/ Speech Production & $\mathrm{r}=0.15$ \\
& $\mathrm{p}=0.25$ \\
\hline Speech Perception/ Music Production & $\mathrm{r}=0.17$ \\
& $\mathrm{p}=0.22$ \\
\hline
\end{tabular}

\subsection{Analysis of the results}

It is worth stressing that there are significant correlations between perception and production of both music and language, which suggests that students' ability to articulate FL sounds accurately results from their ability to discriminate between phonemes. This relates, too, to the perception and production of intonation patterns. The results also indicate that music perception and music production are good predictors of success in second language learning.

The two hypotheses advanced at the onset of the study have actually been verified. For the first hypothesis (music perception/speech perception link) the correlation coefficient reached 0.49 and the $\mathrm{p}$ value was lower than 0.01 . For the second hypothesis (dependence of speech production on music production) the two aspects correlated positively too, although the correlation coefficient was smaller than in the case of perception ( $r=0.39$, but the $p$ value did not go above 0.01 either).

\subsection{Relevant remarks}

Overall, the study presented in the article provided considerable evidence to support the assumption that musical aptitude is a determinant and a predictor of success in foreign language learning. It also indicated that musical training has a positive effect on FL learning. This being so it is worth pondering on the origin of musical intelligence (aptitude): is it innate or learnt, and if learnt, can it be developed by training. Another issue ensuing from the study is the relationship between the ability to perceive speech sounds and the ability to produce them. 


\section{Musical capacity: innate or learnt?}

Test results showed that, on the one hand, MSs outperformed the nMSs and that all musically trained students did better than those musically untrained, on the other. The question that appears is whether high scores reflected solely a natural talent or musical experience (training and/or education). However, this has to be left unanswered since information on the age when the students started musical training, its length and type of training they received was unavailable. Thus further studies in this area are needed to establish the interdependence and to assess the strength of the relation between musical training and speech perception and the effect of this training on speech production (phonetic performance).

Some scholars maintain that success in music depends on both inborn abilities and extensive practice. For example, Gordon (cited in Humphreys, 1998: 45) claims that "the development of musical abilities is based on interaction between innate capacities and environment. Depending on environmental conditions the relative importance of innate differences changes". Humphreys (1998) claims that musical talent can be reinforced by motivation and/or encouragement provided by the student's family and the environment, or stimulated by his/her personality and determination. He also points out that activities like music and different types of creative work are particularly attractive to introverted children.

Claims are also advanced that the human mind is better developed if musical training begins before the age of seven (Miché, 2002). Concerning the music potential itself it is postulated, too, that one either possesses or does not possess it at all. The extent of the gift in every individual is different and musical talent needs to be developed by training. Yet, concerning the influence of musical aptitude on language skills, it is possible to take into account the components that may or may not occur in an individual: one can be naturally endowed with a good sense of rhythm, ability to discriminate frequencies, etc.

\section{Perception versus production}

According to other claims perception determines production and, conversely, production stems from perception (cf., e.g., Tomatis 1991); thus difficulty in perceiving phonemic distinctions will cause articulatory problems. Still others suggest that inaccurate production of FL sounds is due to learners' weak imitative abilities even if their perception is accurate (Purcell and Sutter, 1981).

Our study indicates that speech perception correlates positively with speech production. Therefore we postulate that the ability to perceive speech sounds includes the ability to imitate them. This, however, should be taken as a possibly too hasty overgeneralization since a number of various factors affect both perception and production. Purcell and Sutter (1981) have suggested that twenty variables determine success in mastering English pronunciation. The following are included among others: age, length of time devoted to language learning, sex, social and emotional factors, mother tongue and aptitude for oral mimicry (cf. p. 284). They also claim that it is perceptiveness and imitating ability that determine success in FL learning: "it is relatively easy to recognize the music of a foreign language, it is more difficult to imitate 
this music" (Purcell and Sutter, 1981: 280). The degree of dissimilarity between L1 and L2 phonological systems is most often cited as crucial for learners' problems in perceiving and producing L2 sound s (Morgan-Carter, 2001).

\section{Conclusion}

The main objective of this article was, first, to examine the postulate that differences in musical aptitude affect the quality of phonetic performance of FL students and, second, verify the supposition that musical aptitude is predictive of success in developing pronunciation accuracy in the target language. The results of the research confirmed that there is a correlation between musical aptitude and perception and production of some aspects of FL phonetic features. Admittedly, the relatively small sample of subjects does not allow compelling generalizations to be made; yet, we propose that musical aptitude can be considered an important predictor of success in foreign/second language learning.

In conclusion, it has to be stressed that musical aptitude and musical training should be regarded as an important factor in the language classroom. For instance, musically talented language learners might be allotted to particular groups where their talent could be taken advantage of, thus making both learning and teaching more effective. Undoubtedly, the question of the influence of musical aptitude on FL learning and of the relation between musical and language aptitudes leaves much room for further research. A number of variables pertinent to and involved in the language acquisition processes, such as sex, age, mother tongue, left-handedness need to be considered to arrive at a better understanding of the relationship between music and language, which can provide methodologists and teachers with appropriate didactic guidelines.

\section{References}

Blickenstaff, C. B. 1963. Musical talents and foreign language learning ability. Modern Language Journal, 47: 359-363.

Gardner, H. 1983. Frames of Mind: The Theory of Multiple Intelligences. New York: Basic.

Gunter, T. C. and A. D. Friederici. 2001. Processing Syntactic Relations in language and Music: An Event-Related Potential Study. The Journal of Cognitive Neuroscience, 10: 717-733.

Humphreys, J. T. 1998. Musical Aptitude Testing: From James McKeen Cattell to Carl Emil Seashore. Humphreys Research Studies in Music Education. 10: 42-53.

Miché, M. 2002. Weaving Music into Young Minds. Albany, NY: Delmar.

Morgan-Carter, C. 2001. The Relation between Musical Ear and L2 Acquisition. Vancouver: University of British Columbia. Dept. of Linguistics.

Purcell E. and R. Suter 1981. Predictors of Pronunciation accuracy: reexamination. Language Learning 30: 271-287.

Skehan, P. 1989. Individual differences in second language learning. London: Edward Arnold.

Spiro, J. 2003. Music and the brain. Nature Neuroscience, 6(7): 661-670. 
Tomatis, A. 1991. Pourquoi Mozart? Paris: Fixot.

Zybert, J. 2000. Uzdolnienia do nauki języka obcego - mit czy rzeczywistość? Scripta Neophilologica Posnaniensia. Vol. II, p. 191-199. Poznań: UAM. 